\title{
Strategic marketing - some conceptual and operational reviews from structured marketing works
}

\author{
Bogdan Nichifor, „Vasile Alecsandri” University, Bacău
}

\begin{abstract}
:
Strategic marketing has been for a long time widely recognized as an important aspect of activity of modern organizations. Knowing it characteristics and its role in organizational management is extremely important in developing a long-time efficient business. This article focuses on presenting some synthetic conclusions extracted from the structured strategic marketing works of well-known marketing authors.
\end{abstract}

\section{Key words:}

strategic marketing, marketing strategy, processes.

\section{The role of strategic marketing - a synthetic view}

Strategic marketing represents the process of strategy development, based on marketoriented view, which consider both the changes which are taken place in business environment and the necessity to offer superior value to consumer. The scope of such a process is the one which favor organizational performances and not sales growths. From this point of view, we can see that marketing strategy has the role to deliver superior value to the consumer by combining consumer influence strategies in a coordinated set of actions based on market orientation. Strategic marketing is responsible in assuring the link between the organization and environment, establishing the process of marketing as a responsibility of the whole business and not as the one specific only to a specialized function.

Because of the traditional association among marketing process and set of identifiable entities such as: organization, consumers, marketing channels, competitors, marketing has an enormous significance for the whole strategic planning process at the business level. Strategic marketing gives an important expertise in: environment monitoring, market segments to be targeted, defining strategic guidelines for product development, selecting competitors to fight to. The successful integration of the interfunctional strategies of the business increases the chances to deliver the superior value wanted by the consumer.

\section{Back to marketing strategy}

Strategy can be defined as the knowledge regarding the position in which the organization wishes to be and the path followed to be in this position. From this point of view, strategic marketing can be easily associated to the manager decision regarding the markets in which to compete and the way followed to penetrate these markets. An efficient marketing strategy is based on four behavioral aspects: market receptiveness, developing valid forecasts regarding the environment dynamic and the 
behavior of the markets, exploitation of organizational competences and developing an realistic base for obtaining and maintaining competitive advantage.

Marketing strategy is not developed in isolation; it presumes a correlation with the corporate plan. At the corporate level, marketing inputs (competition screening, the dynamic of the market, and the changes in the environment) are essential in formulating strategic corporate plan. The marketing process represents the interface between the organization and the market and the knowledge about the current conditions in the market are extremely important for all the strategic planning exercises.

In a certain conditions, marketing strategy operates with three essential elements, known as $3 \mathrm{C}$ : consumer, completion and corporation. Marketing strategies are focusing on the way in which corporation can effectively differentiate from the competitors, capitalizing its own strengths in offering superior value to the consumer. An efficient marketing strategy should be characterized by a number of premises: a clear definition of market, a solid correspondence between strengths of the organization and the market needs, superior competitive performance in the key aspects of the business. Together, all three aspects define the triangle of marketing strategy.

Formulating marketing strategies on the base of the three aspects make necessarily the next actions:

- Where to compete, this decision makes necessarily defining the market;

- How to compete, this decision asks for identifying the instruments to be used;

- When to compete, this decision asks for temporal planning of market entry. Knowing all that, we can define marketing strategy as the process of creating a unique and valuable position, which imply a set of different activities. Developing marketing strategy asks for selections of those activities which are different from those of the competitors.

\section{Essentials of strategic marketing}

The core specific aspects of strategic marketing are:

1. Focusing on long term implications. The decisions specific to strategic marketing have implications on long term. In other words, strategic marketing means engagement and not action. Efficient monitoring of environment asks for strategic inputs. These inputs are different from one specific to marketing research because they ask for more detailed analysis.

2. Corporate inputs. Strategic marketing decisions need the existence of the inputs from three sources: corporate culture, corporate public and corporate resources. Corporate culture engages: style, characteristics, taboos, rituals of the superior management, which over the time are recognized as being organizational intrinsic. Corporate public includes different categories of public with an concern regarding the existence of the organization. These categories are: consumers, employs, trade partners, government and community. Corporate resources include financial, human, physical and technologic resources specific to the organization. Corporate inputs establish the degree of freedom of the manager regarding the market to penetrate the business to invest or to abandon.

3. Different role for strategic unit. Traditionally, it has been considered that all the products ask for efforts to maximize the profit. Strategic marketing adopt the premise that the products have different roles for the organization. The practices specific to strategic marketing try to identify the characteristics of 
every strategic unit before establishing its role. Moreover, different strategic units are synergic associated to maximize the marketing effort. Finally, each strategic unit is delegated to a manager, which has the necessary experience and skills to manage it properly.

4. Organizational levels. Strategic marketing is primary developed at strategic unit level.

5. Relation with the financial dimension. The decisions specific to strategic marketing are closely related to financial dimension of organizational activity. The importance of maintaining a close relationship between marketing and finance is not a new organizational aspect. Strategic marketing doesn't have a linear evolution. In the 1970, turbulent environment forced the managers to develop strategic plans for a better efficient and centralized management of the resources. All these plans had an important financial dimension. It has been widely recognized that the marketing inputs are necessary, but are they obtained when it is needed or are they considered as already given. For example, the majority of strategic planning actions focus on cash-flow and investments return, both associated to market share. The market share can be in the same way approached in two terms: it is considered as constant or it is considered to be ad-hoc obtained. As a conclusion, marketing inputs, such as market share, have to be seen as results and not causes.

\section{Important in the past, as well as in the future}

A number of factors point to the important role of which strategic marketing is playing. First, the battle for market share is intense both in mature and new markets. Strategic marketing is an indispensable instrument in such conditions. Second, the turbulent market conditions ask again for strategic marketing. Third, the battle between producers and distributors market share engages strategic marketing on both sides. Tradition marketing channels have become relative, many producers being in the same time wholesalers, retailers, buying groups etc. In specific situations, distributors and producers representatives play an important role, in other buying groups and cooperatives play a more important role. Fourth, international competition has become more intense. More and more countries develop new capacities which let them to be more competitive in international markets. These countries are ready to learn, to adapt and to innovate, being interested in improving economical conditions and life standards. Fifths, market fragmentation lead to growing strategic marketing importance. Competitive realities of the markets make necessary the existence of strategic marketing instruments to be used in identifying market segments and launching new products. Sixth, facile access to technology and short-term product life-cycle favor the rapid moving marketers. Rapid moving marketers have to have an important expertise in strategic marketing. Seventh, the new millennium asks for identifying new competitive spaces, in which the organization is the only leader. Corporate imagination and strategic based policies are essential in developing new markets.

Knowing all this facts, modern organization has to implement strategic marketing within its core culture and business practices as a premise of successful long-term existence. The next figure shows how strategic marketing process can be developed in order to ensure a systematical approach of all marketing decisions. 


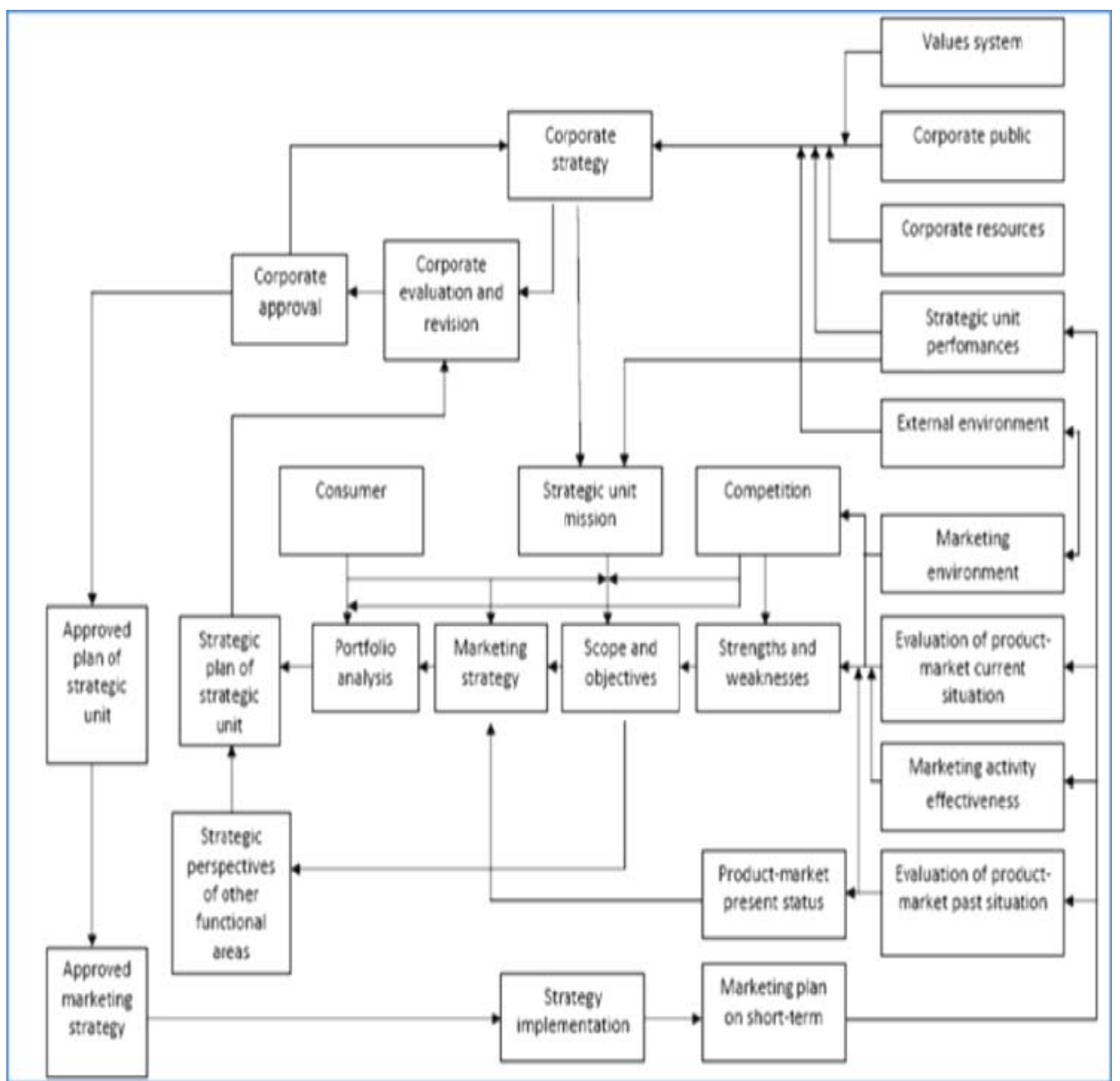

Figure 1. The process of strategic marketing

Sursa: Jain, S.C., Marketing, Planning and Strategy, South Western College Publishing, Cincinatti, 2000, p. 35 .

\section{Bibliography}

1. Cravens, D., Piercy, N. (2008), Strategic Marketing, Mcgraw Hill/Irwin

2. Gilligan, C., Wilson, R. (2003), Strategic Marketing Planning, Butterworth-Heinemann

3. Jain, S.C. (2000), Marketing, Planning and Strategy, South Western College Publishing, Cincinatti 